\title{
Discontinuation of antiviral prophylaxis correlates with high prevalence of hepatitis B virus (HBV) reactivation in rheumatoid arthritis patients with HBV carrier state: a real-world clinical practice
}

Ying-Qian Mo ${ }^{1 \dagger}$, An-Qi Liang ${ }^{1 \dagger}$, Jian-Da Ma ${ }^{1}$, Le-Feng Chen ${ }^{1}$, Dong-Hui Zheng ${ }^{1}, \mathrm{H}$ Ralph Schumacher ${ }^{2}$ and Lie Dai ${ }^{*}$

\begin{abstract}
Background: To investigate the risk of hepatitis B virus (HBV) reactivation in rheumatoid arthritis (RA) patients with HBV carrier state during treatment of disease-modifying antirheumatic drugs (DMARDs) and the use of antiviral prophylaxis in real-world clinical practice.

Methods: Consecutive RA patients with HBV carrier state were included. Clinical data including liver evaluation, HBV infection evaluation and the use of antiviral prophylaxis were recorded.

Results: Fifty-three RA patients with HBV carrier state were screened and 36 patients were qualified for analysis. Thirty-six percentage of patients developed HBV reactivation and 17\% developed HBV hepatitis together with reactivation, one of which developed decompensate cirrhosis. Only 50\% of patients accepted lamivudine although all patients were recommended antiviral prophylaxis with entecavir or tenofovir and only $31 \%$ continued during DMARDs therapy. Seventy-one percentage of patients who discontinued antiviral prophylaxis developed HBV reactivation $3 \sim 21$ months after discontinuation. Logistic regression analyses showed discontinuation of antiviral prophylaxis (OR: 66, $p=0.027$ ), leflunomide (OR: $64, p=0.011)$ and past history of hepatitis (OR: $56, p=0.013)$ were risk factors of HBV reactivation. Past history of hepatitis (OR: 10, $p=0.021)$ was also risk factor of HBV hepatitis together with reactivation.
\end{abstract}

Conclusion: Our results suggest poor patient acceptance and discontinuation of antiviral prophylaxis should not be ignored for Chinese RA patients with HBV carrier state in real-world clinical practice. Discontinuation of antiviral prophylaxis, past history of hepatitis and LEF might increase risk of HBV reactivation for RA patients with HBV carrier state during DMARDs therapy.

Keywords: Rheumatoid arthritis, Hepatitis B virus, Disease-modifying antirheumatic drugs

\section{Background}

Chronic hepatitis B virus (HBV) infection is defined as the presence of positive surface antigen of $\mathrm{HBV}(\mathrm{HBsAg})$ more than 6 months and generally classified into HBV hepatitis with fluctuant alanine amino-transferase (ALT) and HBV carriers state with persistent normal ALT.

\footnotetext{
*Correspondence: liedai2004@163.com

${ }^{+}$Equal contributors

'Department of Rheumatology, Sun Yat-sen Memorial Hospital, Sun Yat-Sen University, 107\# Yan Jiang West Road, Guangzhou 510120, People's Republic of China

Full list of author information is available at the end of the article
}

Chronic HBV infection is a global healthcare problem affecting more than 350 million people around the world with potential poor prognosis of cirrhosis, hepatocarcinoma or death $[1,2]$. Our previous study reported the prevalence of chronic HBV infection among Chinese rheumatoid arthritis (RA) patients was $11.2 \%$, similar with the prevalence of the age-matched general Chinese population [1,3]. It is estimated 300,000 600,000 Chinese RA patients with chronic HBV infection.

The prevalence of HBV reactivation was estimated $50 \%$ among patients with hematology-oncology diseases 
during immunosuppressive therapy and it may lead to severe outcomes including hepatitis, acute liver failure, cirrhosis or death in $5 \% \sim 30 \%$ of patients [4]. International associations for the study of liver disease recommended antiviral prophylaxis should be used before immunosuppressive therapy and continued minimal $6 \sim 12$ months after suspension of immunosuppressant for chronic HBV infection patients [5-7], based on clinical evidences derived from hematology-oncology field. However, there're great differences of host immune status, the types and intensity of immunosuppressant between RA patients and hematology-oncology patients.

Recommendations for disease-modifying antirheumatic drugs (DMARDs) from American College of Rheumatology (ACR) in 2008 suggested that minocycline, sulfasalazine (SSZ) under antiviral prophylaxis and hydroxychloroquine (HCQ) could be used for RA patients with HBV carrier state and liver function of Child-Pugh class A (a scoring system for chronic liver disease), while methotrexate (MTX) and leflunomide (LEF) were contraindicated [8]. ACR 2012 update recommended that biologic DMARDs should also be used with antiviral prophylaxis in these patients [9]. That is to say, long-term antiviral prophylaxis should be used for RA patients with HBV carrier state due to long-term DMARDs treatment. However, in real-world clinical practice, antiviral prophylaxis may not be continued even not accepted due to high economic burden, poor patient compliance or efficacy/safety of antiviral drugs. To explore the risk of HBV reactivation in RA patients with $\mathrm{HBV}$ carrier state during DMARDs therapy and the use of antiviral prophylaxis in real-world clinical practice, here we reported our single center results.

\section{Methods}

\section{Patients}

Consecutive and hospitalized RA patients from July 2007 to September 2013 at department of Rheumatology, Sun Yat-Sen Memorial Hospital, Sun Yat-Sen University were screened. All RA patients fulfilled 1987 ACR revised criteria or 2010 ACR/European League Against Rheumatism (EULAR) criteria. RA Patients with HBV carrier state who had positive HBsAg, normal ALT $\geq 6$ months and normal total billirubin (TBiL) were included. Patients with HBV hepatitis or other types of viral hepatitis, autoimmune hepatitis, drug-induced hepatitis, cirrhosis or hepatocarcinoma were excluded. All patients gave written informed consent for this study, which was approved by the Ethics Committee of Sun Yat-Sen Memorial Hospital.

\section{Study design}

Clinical data such as demographic characteristics, RA disease activity evaluation, liver evaluation, HBV infection evaluation and therapeutic regimens were recorded during follow-up period without interference with physicians' therapeutic strategies. Liver evaluation included serum ALT, TBiL and if necessary, liver ultrasonography. $\mathbf{H B V}$ infection evaluation included serum HBV-DNA and HBV serological markers including HBsAg and its antibody (HBsAb), antigen e of HBV (HBeAg) and its antibody ( $\mathrm{HBeAb})$, antibody to $\mathrm{HBV}$ core antigen (HBcAb). Serum HBV-DNA was detected by quantitative real-time PCR by fluorogenic probe method with a lower limit of detection of $10^{3}$ copies $/ \mathrm{mL}$. HBV serological markers were qualitatively detected by ELISA.

\section{Outcomes}

The primary outcome was HBV reactivation, which was defined as a 10-fold rise in HBV-DNA compared to baseline or a switch from undetectable to detectable, and/or HBeAg seroconversion from negative to positive [4]. The secondary outcome was HBV hepatitis defined as ALT $>80 \mathrm{U} / \mathrm{L}$ after reactivation, with or without icterus [10].

\section{Statistical analysis}

Statistical analysis was performed with SPSS for Windows 13.0 (SPSS Inc., Chicago, IL, USA). The non-parametric Mann-Whitney U test or Fisher's exact probabilities test were used for between-group comparison. Survival curve by Kaplan-Meier method and log-rank test was used to estimate the occurrence time of HBV reactivation. Stepforward logistic regression analysis was used to find out the risk factors of HBV reactivation and the following $\mathrm{HBV}$ hepatitis, counting odds ratio (OR) and its 95\% of confidence interval $(\mathrm{CI})$. A p-value of less than 0.05 was considered to be significant.

\section{Results}

\section{Baseline characteristics of the study patients}

Four hundred and ninety-six consecutive and hospitalized RA patients were screened. Three patients with HCV hepatitis, one patient overlapping with autoimmune hepatitis and two patients with drug-induced hepatitis were excluded. None of these six patients had positive HBsAg. Seven patients with HBV hepatitis were not included either.

Fifty-three RA patients with HBV carrier state were included. Two patients overlapping with systemic lupus erythematosus and one patient combined with lower limbs vasculitis were excluded due to high-dose corticosteroids or different immunosuppressants (e.g. cyclophosphamide). Eight patients were unwilling to be followed up. Six patients lost follow-up due to home migration or change to Chinese herbal therapy. Finally, 36 patients were qualified for statistics (Figure 1). Their baseline characteristics were shown in Table 1 . Twenty-six patients (72\%) were in 


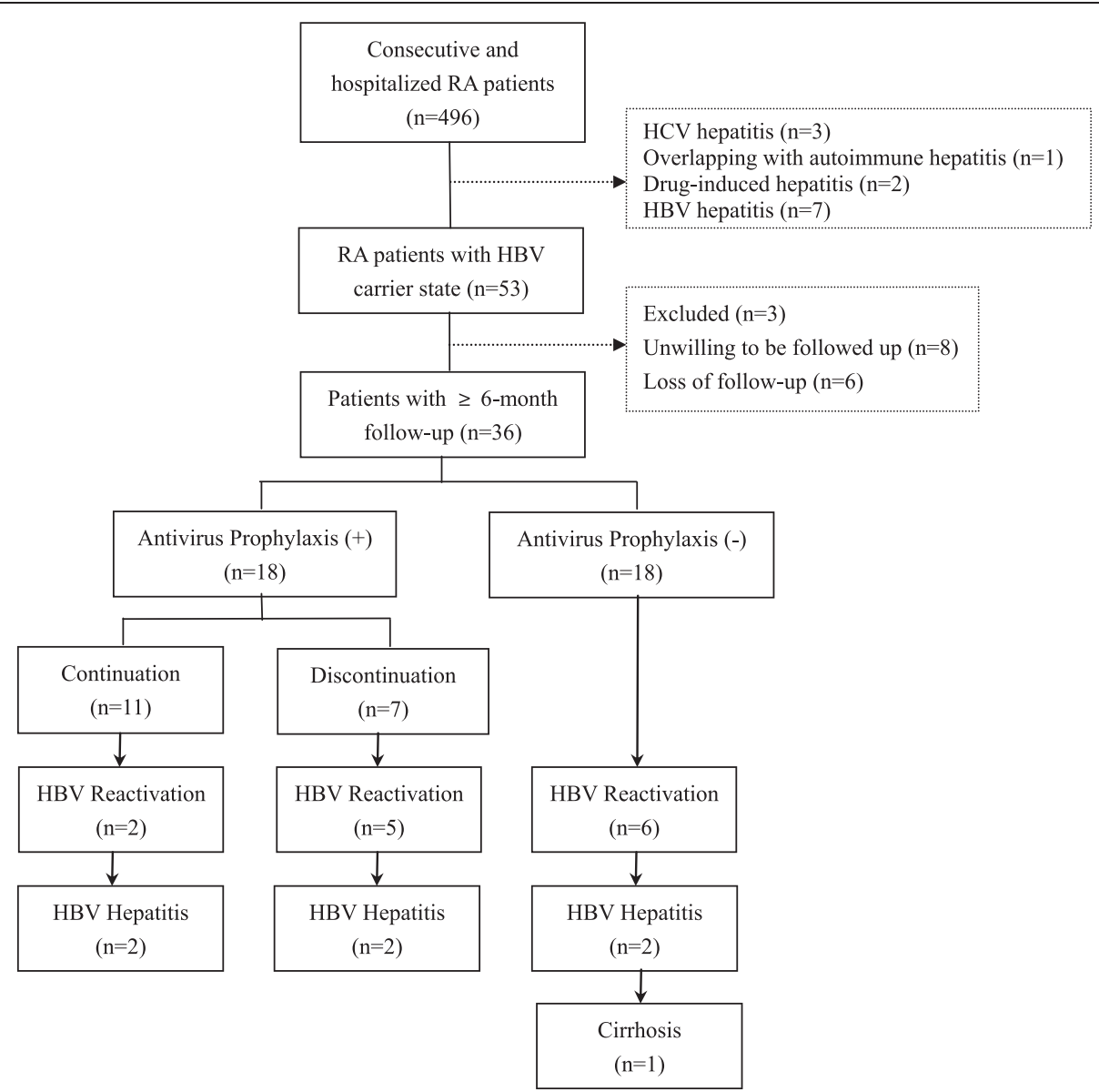

Figure 1 Flowchart shows the development of hepatitis B virus (HBV) reactivation in rheumatoid arthritis (RA) patients with HBV carrier state with and without antiviral prophylaxis and who discontinued antiviral prophylaxis.

moderate to high disease activity according to DAS28-crp. Before enrollment, 24 patients $(67 \%)$ had never received any DMARD or corticosteroid, while the other 12 patients had received corticosteroid $(n=8)$, MTX $(n=9)$, LEF $(\mathrm{n}=8)$, SSZ $(\mathrm{n}=4)$ or HCQ $(\mathrm{n}=1)$.

Serum HBV-DNA was undetectable $\left(<10^{3}\right.$ copies $\left./ \mathrm{mL}\right)$ in 20 patients and the median of serum HBV-DNA in the other 16 patients was $4.2 \times 10^{4}$ copies $/ \mathrm{mL}$ (range, $1 \times 10^{3} \sim 1.5 \times 10^{8}$ ). Positive HBeAg was detected in 2 patients with undetectable HBV-DNA and 5 patients with detectable HBV-DNA. There was no significant difference of baseline characteristics between patients with undetectable and detectable HBV-DNA, except that ALT was significantly higher in the latter than in the former $(\mathrm{P}<0.05$, Table 1$)$ and both ALT were not exceeding normal range.

\section{$\mathrm{HBV}$ reactivation in RA patients with $\mathrm{HBV}$ carrier state} Antiviral prophylaxis was recommended for all RA patients with HBV carrier state, but only 18 patients (50\%) accepted. Entecavir and tenofovir were recommended to these patients. However, only lamivudine was accepted for economic reason. Sixty-three percentage $(10 / 16)$ of patients with detectable baseline HBV-DNA accepted antiviral prophylaxis, which tended to be higher than $40 \%(8 / 20)$ of patients with undetectable baseline HBV-DNA (Table 2), but no statistical significance between these two groups was found. Three of seven patients with positive $\mathrm{HBeAg}$ accepted antiviral prophylaxis. The median follow-up period was 17.5 months (range, $12 \sim 70$ months). HBV-DNA and HBV serological markers of each included patient both at baseline and at the end of follow-up were shown in Additional file 1.

Thirty-six percentage (13/36) of RA patients with HBV carrier state developed HBV reactivation during DMARDs therapy and 17\% (6/36) developed HBV hepatitis together with reactivation. Among patients with undetectable baseline HBV-DNA, 40\% (8/20) had a switch of serum HBV-DNA from undetectable to detectable. Among patients with detectable baseline HBV-DNA, $31 \%(5 / 16)$ had a 10 -fold rise in serum HBV-DNA 
Table 1 Baseline characteristics and therapeutic regimens during follow-up of 36 RA patients with hepatitis B virus (HBV) carrier state ${ }^{\wedge}$

\begin{tabular}{|c|c|c|c|}
\hline & \multirow[t]{2}{*}{ All Patients $(n=36)$} & \multicolumn{2}{|c|}{ Baseline serum HBV DNA } \\
\hline & & Undetectable $(n=20)$ & Detectable $(n=16)$ \\
\hline \multicolumn{4}{|l|}{ Demographic characters } \\
\hline Age (years) & $46 \pm 15$ & $45 \pm 15$ & $48 \pm 16$ \\
\hline Female proportion & $28(78 \%)$ & $14(70 \%)$ & $14(88 \%)$ \\
\hline \multicolumn{4}{|l|}{ Disease status } \\
\hline Disease duration (months), median (range) & $21(2 \sim 360)$ & $11(2 \sim 240)$ & $24(2 \sim 360)$ \\
\hline Past history of hepatitis & $9(25 \%)$ & $5(25 \%)$ & $4(25 \%)$ \\
\hline DAS28-crp, mean \pm SD (range) & $4.2 \pm 1.6(1.2 \sim 7.6)$ & $4.4 \pm 1.7(1.2 \sim 7.4)$ & $3.9 \pm 1.6(1.7 \sim 7.6)$ \\
\hline RF positive rate & $21(58 \%)$ & $11(55 \%)$ & $10(63 \%)$ \\
\hline Anti-CCP antibody positive rate & $17(47 \%)$ & $12(60 \%)$ & $5(31 \%)$ \\
\hline CRP (mg/L) & $25 \pm 33$ & $28 \pm 35$ & $20 \pm 32$ \\
\hline $\operatorname{ESR}(\mathrm{mm} / 1 \mathrm{~h})$ & $49 \pm 43$ & $55 \pm 48$ & $40 \pm 35$ \\
\hline $\mathrm{ALT}(\mathrm{U} / \mathrm{L})$ & $19 \pm 10$ & $17 \pm 12$ & $21 \pm 6^{\#}$ \\
\hline Total bilirubin $(\mu \mathrm{mol} / \mathrm{L})$ & $8 \pm 4$ & $8 \pm 2$ & $11 \pm 5$ \\
\hline \multicolumn{4}{|l|}{ Therapeutic regimens during follow-up } \\
\hline MTX & $3(8 \%)$ & $2(10 \%)$ & $1(6 \%)$ \\
\hline LEF $^{*}$ & $2(6 \%)$ & $2(10 \%)$ & $0(0 \%)$ \\
\hline $\mathrm{HCQ}$ & $1(3 \%)$ & $0(0 \%)$ & $1(6 \%)$ \\
\hline MTX + LEF & $5(14 \%)$ & $3(15 \%)$ & $2(13 \%)$ \\
\hline $\mathrm{MTX}+\mathrm{SSZ}$ & $3(8 \%)$ & $2(10 \%)$ & $1(6 \%)$ \\
\hline MTX + HCQ & $10(28 \%)$ & $4(20 \%)$ & $6(38 \%)$ \\
\hline $\mathrm{MTX}+\mathrm{HCQ}+\mathrm{SSZ}$ & $12(33 \%)$ & $7(35 \%)$ & $5(31 \%)$ \\
\hline Low-dose Corticosteroid & $29(81 \%)$ & $15(75 \%)$ & $14(88 \%)$ \\
\hline TNF-a antagonist $^{\Delta}$ & $4(11 \%)$ & $4(20 \%)$ & 0 \\
\hline
\end{tabular}

$\triangle$ Data were described with mean \pm standard deviation (SD) or number (precentage) unless stated otherwise. DAS28-crp $=$ Disease Activity Score with 28 -joint counts modified by $C R P ; R F=$ rheumatoid factor; anti-CCP = anti-cyclic citrullinated peptide antibody; $C R P=C$-reactive protein; ESR $=$ erythrocyte sedimentation rate; $\mathrm{ALT}=$ alanine aminotransferase; $\mathrm{MTX}=$ methotrexate; $\mathrm{LEF}=$ leflunomide; $\mathrm{SSZ}$ = sulfasalazine; $\mathrm{HCQ}=$ hydroxychloroquine; $\mathrm{NSAIDs}=$ non-steroidal anti-inflammatory drugs; $\mathrm{TNF}=$ tumor necrosis factor.

*Patients with MTX intolerance due to gastrointestinal discomfort.

$\Delta$ recombinant human TNF-areceptor: IgG Fc fusion protein $(50 \mathrm{mg} / \mathrm{w}$ ) was given to 2 patients for 4 weeks and infliximab was given to the other 2 patients at a dose of $200 \mathrm{mg}$ for 3 times.

${ }^{\#}$ Compared to patients with undetectable baseline HBV DNA, $\mathrm{P}<0.05$.

(Table 2). There was no significant difference in the prevalence of HBV reactivation between the above two groups of patients ( $p>0.05$, Table 2$)$. Clinical, serological and virological characteristics of all 13 RA patients with HBV reactivation were shown in Table 3 . None of them accompanied with $\mathrm{HBeAg}$ seroconversion from negative to positive.
Risk factors of HBV reactivation in RA patients with HBV carrier state

Therapeutic regimens for RA during follow-up were shown in Table 1. Low-dose MTX $(\leq 15 \mathrm{mg} / \mathrm{w})$ or MTX + LEF therapy was prescribed for patients responding insufficiently to the original $\operatorname{DMARD}(\mathrm{s})$ therapy, intolerant to other DMARDs, in moderate to high disease

Table 2 Antiviral prophylaxis, HBV reactivation and HBV hepatitis between RA patients with undetectable and detectable baseline HBV-DNA

\begin{tabular}{lllllll}
\hline Baseline HBV DNA & \multicolumn{2}{l}{ Antiviral prophylaxis } & & \multicolumn{2}{l}{ HBV reactivation } & HBV hepatitis \\
\cline { 2 - 5 } & Yes* & Discontinuation & No & & \\
\hline Undetectable $(\mathbf{n}=\mathbf{2 0})$ & $4(20 \%)$ & $4(20 \%)$ & $3(19 \%)$ & $6(37 \%)$ & $5(31 \%)$ & $4(25 \%)$ \\
\hline Detectable $(\mathbf{n}=\mathbf{1 6})$ & $7(44 \%)$ & $(10 \%)$ & \\
\hline
\end{tabular}

*Patients who discontinued antiviral prophylaxis were not included.

$\Delta$ all $P>0.05$. 
Table 3 Clinical, serological and virological characteristics in 13 rheumatoid arthritis (RA) patients with HBV reactivation during immunosuppressive therapy Patient 12 Patient 20 Patient 3 Patient 4 Patient 5 Patient 6 Patient 7 Patient 8 Patient 9 Patient 10 Patient 11 Patient 12 Patient 13

\begin{tabular}{|c|c|c|c|c|c|c|c|c|c|c|c|c|c|}
\hline Age/Gender & $53 / \mathrm{M}$ & $39 / \mathrm{F}$ & $42 / \mathrm{F}$ & $54 / \mathrm{F}$ & $71 / \mathrm{F}$ & $26 / \mathrm{F}$ & $45 / \mathrm{F}$ & $55 / F$ & $36 / \mathrm{F}$ & $54 / \mathrm{M}$ & $17 / F$ & $21 / \mathrm{M}$ & $51 / F$ \\
\hline Past history of hepatitis & no & yes & no & no & no & yes & no & no & no & yes & yes & yes & yes \\
\hline HBeAg, baseline/reactivation & $-1-$ & $-1-$ & $-1-$ & $-1-$ & $-1-$ & $-1-$ & $+/+$ & $-1-$ & $-1-$ & $-1-$ & $+/+$ & $+/+$ & $-1-$ \\
\hline $\begin{array}{l}\text { Viral loads at baseline } \\
\text { (Copies } / \mathrm{mL} \text { ) }\end{array}$ & $<10^{3}$ & $<10^{3}$ & $<10^{3}$ & $1.0 \times 10^{3}$ & $<10^{3}$ & $<10^{3}$ & $<10^{3}$ & $<10^{3}$ & $7.03 \times 10^{3}$ & $1.22 \times 10^{3}$ & $3.18 \times 10^{5}$ & $<10^{3}$ & $1.0 \times 10^{3}$ \\
\hline $\begin{array}{l}\text { Viral loads at reactivation } \\
\text { (Copies } / \mathrm{mL} \text { ) }\end{array}$ & $3.64 \times 10^{5}$ & $7.87 \times 10^{3}$ & $1.92 \times 10^{3}$ & $2.47 \times 10^{4}$ & $6.98 \times 10^{3}$ & $1.15 \times 10^{4}$ & $3.01 \times 10^{3}$ & $4.01 \times 10^{3}$ & $9.91 \times 10^{5}$ & $1.41 \times 10^{7}$ & $1.78 \times 10^{8}$ & $5.26 \times 10^{7}$ & $1.59 \times 10^{7}$ \\
\hline ALT at baseline (U/L) & 8 & 8 & 20 & 19 & 10 & 6 & 15 & 15 & 11 & 30 & 17 & 20 & 27 \\
\hline ALT at reactivation (U/L) & 26 & 20 & 39 & 24 & 26 & 8 & 16 & 123 & 103 & 103 & 825 & 1880 & 1274 \\
\hline
\end{tabular}

Therapeutic regimens during follow-up

\begin{tabular}{|c|c|c|c|c|c|c|c|c|c|c|c|c|c|}
\hline Corticosteroid & $7.5-10 \mathrm{mg} / \mathrm{d}$ & no & no & $2.5-10 \mathrm{mg} / \mathrm{d}$ & $5-10 \mathrm{mg} / \mathrm{d}$ & $10 \mathrm{mg} / \mathrm{d}$ & $10 \mathrm{mg} / \mathrm{d}$ & $2.5-10 \mathrm{mg} / \mathrm{d}$ & $10 \mathrm{mg} / \mathrm{d}$ & $7.5-10 \mathrm{mg} / \mathrm{d}$ & $7.5-10 \mathrm{mg} / \mathrm{d}$ & no & $5-7.5 \mathrm{mg} / \mathrm{d}$ \\
\hline DMARDs & $M T X+L E F$ & $\begin{array}{l}\mathrm{MTX}+\mathrm{HCQ}+ \\
\mathrm{SSZ}\end{array}$ & $M T X+L E F$ & $\mathrm{MTX}+\mathrm{HCQ}$ & $\mathrm{MTX}+\mathrm{SSZ}$ & LEF & $\begin{array}{l}\mathrm{MTX}+\mathrm{HCQ}+ \\
\mathrm{SSZ}\end{array}$ & $M T X+L E F$ & $\begin{array}{l}\mathrm{MTX}+\mathrm{HCQ}+ \\
\mathrm{SSZ}\end{array}$ & $\mathrm{MTX}+\mathrm{HCQ}$ & $M T X+L E F$ & LEF & $\begin{array}{l}\mathrm{MTX}+\mathrm{HCQ}+ \\
\mathrm{SSZ}\end{array}$ \\
\hline Antiviral prophylaxis & no & Dis & no & Dis & Dis & no & no & no & LAM & LAM & Dis & Dis & no \\
\hline Time to reactivation (months) & 22 & 24 & 26 & 15 & 10 & 18 & 3 & 22 & 8 & 14 & 5 & 6 & 25 \\
\hline Follow-up period (months) & 33 & 43 & 34 & 25 & 22 & 35 & 6 & 52 & 10 & 18 & 11 & 7 & 25 \\
\hline HBV hepatitis & no & no & no & no & no & no & no & Anicteric & Anicteric & Anicteric & Icteric & Icteric & $\begin{array}{l}\text { Icteric, } \\
\text { cirrhosis }\end{array}$ \\
\hline \multicolumn{14}{|c|}{ Treatment adjustment after HBV reactivation } \\
\hline Adjustments in DMARDs & $\begin{array}{l}\mathrm{MTX}+\mathrm{HCQ}+ \\
\mathrm{SSZ}\end{array}$ & no & no & no & no & no & no & $\mathrm{HCQ}$ & $\begin{array}{l}\mathrm{MTX}+\mathrm{HCQ}+ \\
\mathrm{SSZ}\end{array}$ & $\mathrm{HCQ}$ & SSZ & $\mathrm{HCQ}$ & withdrawal \\
\hline Antiviral drugs & LAM & no & no & no & no & no & no & LAM & $\begin{array}{l}\text { Adefovir } \\
\text { dipivoxil }\end{array}$ & telbivudine & LAM & entecavir & telbivudine \\
\hline
\end{tabular}

$\triangle$ The sequences of patients were numbered according to the date of HBV reactivation.

$\mathrm{HBV}=$ Hepatitis $\mathrm{B}$ virus; $\mathrm{F}$ = female; $\mathrm{M}$ = male; $\mathrm{HBeAg}=$ antigen e of $\mathrm{HBV} ; \mathrm{ALT}=$ alanine aminotransferase; $\mathrm{DMARDs}=$ disease-modifying antirheumatic drugs; $M T \mathrm{TX}=$ methrotrexate; $\mathrm{LEF}=\mathrm{Leflunomide;} \mathrm{HCQ}=$ hydroxychloroquine; SSZ = sulfasalazine.

Dis = Discontinuation; LAM = lamivudine. 
activity or with prognostically unfavourable factors. Four of 5 patients (80\%) taking MTX + LEF developed HBV reactivation, which was significantly higher than $21 \%(6 / 28)$ in patients taking MTX alone or other MTX-based DMARD combinations, $\mathrm{p}=0.021$, Fisher's Exact Test. Four patients have received TNF- $\alpha$ antagonist for $4 \sim 6$ weeks. After receiving TNF- $\alpha$ receptor: IgG Fc fusion protein (50 mg/w) for 4 weeks, one of two patients changed to MTX + LEF therapy for economic reason and developed HBV reactivation 21 months later (Patient 1 in Table 3); and the other changed to MTX + HCQ + SSZ + Lamivudine therapy and kept undetectable HBV-DNA and normal ALT. After receiving infliximab for 3 times, one of two patients changed to MTX + HCQ + SSZ therapy and developed HBV reactivation 22 months later (Patient 2 in Table 3); and the other changed to MTX + LEF therapy and developed HBV reactivation 24 months later (Patient 3 in Table 3).

Seven of 18 patients discontinued lamivudine 1 7 months later by themselves due to high drug cost and $71 \%$ of them $(5 / 7)$ developed HBV reactivation 3 21 months after discontinuation of lamivudine (Table 3). The prevalence of HBV reactivation in patients who discontinued antiviral prophylaxis was 71\% (5/7), which tended to be higher than $33 \%(6 / 18)$ in patients without antiviral prophylaxis or $18 \%(2 / 11)$ in patients with continuous antiviral prophylaxis (Figure 1), although no significant difference was found perhaps due to small sample size $(p=0.122)$. Notably, survival curve showed the median occurrence time of HBV reactivation in patients who discontinued antiviral prophylaxis was 10 months (95\%CI: $1.7 \sim 18$ months), which was earlier than that in patients without antiviral prophylaxis, 25 months (95\%CI: $20 \sim 30$ months) $\left(x^{2}=10.754, \mathrm{p}=0.005\right.$, Figure 2$)$. Two patients with baseline HBV-DNA of $7.03 \times 10^{3}$ copies $/ \mathrm{mL}$ or $1.22 \times 10^{3}$ copies $/ \mathrm{mL}$ developed HBV reactivation 8 or 14 months later although continuous antiviral prophylaxis with lamivudine (Patient 9 and 10 in Table 3).

Logistic regression analysis was performed on variables including age, past history of hepatitis, baseline HBeAg, baseline load of HBV-DNA, immunosuppressants (such as corticosteroid, MTX, LEF, SSZ, HCQ) and antiviral prophylaxis. Discontinuation of antiviral prophylaxis (OR: 66, $\mathrm{p}=0.027$ ), LEF (OR: 64, $\mathrm{p}=0.011$ ) and past history of hepatitis (OR: 56, $\mathrm{p}=0.013$ ) were risk factors of HBV reactivation for RA patients with HBV carrier state during DMARDs therapy (Table 4). Further analysis showed patients with past history of hepatitis had a higher prevalence of $\mathrm{HBV}$ reactivation than those without, $78 \%$ (7/9) vs. $22 \%$ (6/27), p = 0.005, Fisher's Exact Test.

\section{HBV hepatitis after HBV reactivation in RA patients with HBV carrier state}

Among 13 RA patients with HBV reactivation, 6 patients (46\%) developed HBV hepatitis together with reactivation. Three patients (23\%) developed icteric hepatitis and all of these three patients had past history of icteric hepatitis. Logistic regression analysis on the above variables showed past history of hepatitis was also risk factor of $\mathrm{HBV}$ hepatitis after $\mathrm{HBV}$ reactivation (OR: 10, $\mathrm{p}=0.021$, Table 4). Further analysis showed patients with past history of hepatitis had a higher prevalence of HBV hepatitis following reactivation than those without, 44\% (4/9) vs 7\% (2/27), p = 0.024, Fisher's Exact Test.

The prevalence of HBV hepatitis in patients with HBVDNA $\geq 10^{5}$ copies/mL at reactivation was $83 \%$ (5/6), which was significantly higher than $14 \%(1 / 7)$ in patients with HBV-DNA $<10^{5}$ copies $/ \mathrm{mL}$ at reactivation $(\mathrm{p}=0.029)$.

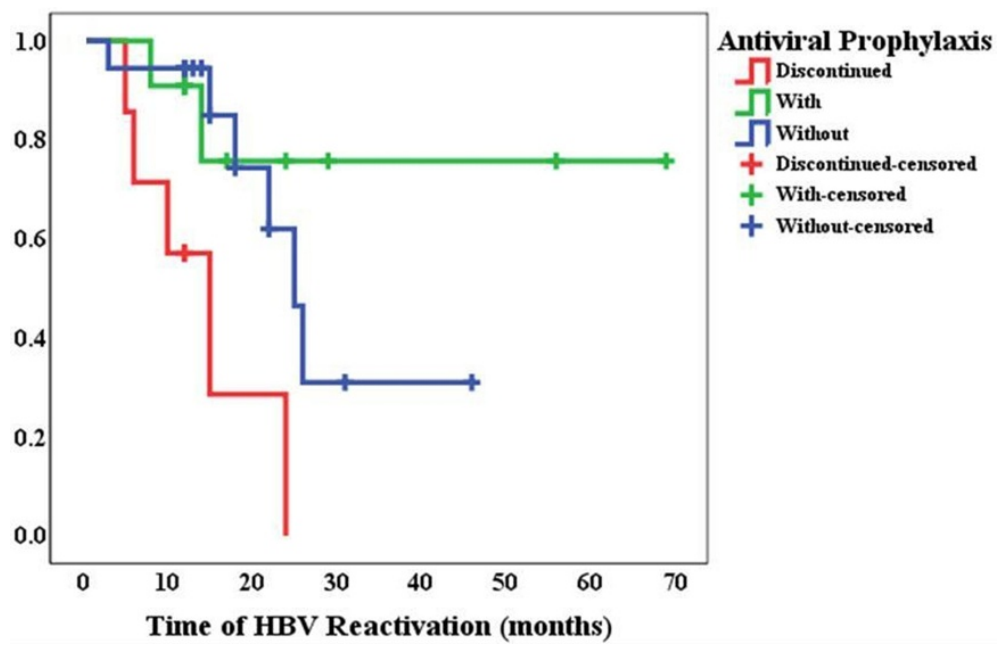

Figure 2 Survival curve of hepatitis B virus (HBV) reactivation in patients with (green) or without antiviral prophylaxis (blue) or those who discontinued antiviral prophylaxis (red) during immunosuppressive therapy. 
Table 4 Step-forward logistic regression analysis on the risk factors of HBV reactivation and HBV hepatitis

\begin{tabular}{|c|c|c|c|c|c|c|c|}
\hline & \multirow[t]{2}{*}{ Coefficient } & \multirow[t]{2}{*}{ Standard error } & \multirow[t]{2}{*}{ Wald $x^{2}$} & \multirow[t]{2}{*}{$\mathbf{P}$} & \multirow[t]{2}{*}{ Odds ratio } & \multicolumn{2}{|l|}{$95 \% \mathrm{Cl}$} \\
\hline & & & & & & Lower & Upper \\
\hline \multicolumn{8}{|l|}{ Risk factors of HBV reactivation } \\
\hline Leflunomide & 4.2 & 1.6 & 6.5 & 0.011 & 64 & 2.6 & 1591 \\
\hline Discontinuation of antiviral prophylaxis & 4.2 & 1.9 & 4.9 & 0.027 & 66 & 1.6 & 2675 \\
\hline Past history of hepatitis & 4.0 & 1.6 & 6.1 & 0.013 & 56 & 2.3 & 1355 \\
\hline Constant & -4.2 & 1.6 & 6.5 & 0.011 & 0.016 & & \\
\hline \multicolumn{8}{|l|}{ Risk factor of HBV hepatitis } \\
\hline Past history of hepatitis & 2.3 & 1.0 & 5.4 & 0.021 & 10 & 1.4 & 70 \\
\hline Constant & -2.5 & 0.7 & 11.8 & 0.001 & 0.08 & & \\
\hline
\end{tabular}

\section{Treatment adjustment after HBV reactivation}

Six of 7 patients with HBV-DNA $<10^{5}$ copies $/ \mathrm{mL}$ at reactivation (patient $2 \sim 7$ in Table 3 ) were followed up closely without antiviral therapy or DMARDs adjustment and their HBV-DNA returned to undetectable $8 \sim 19$ months later. The other one patient with HBV hepatitis although $\mathrm{HBV}-\mathrm{DNA}<10^{5}$ copies $/ \mathrm{mL}$ at reactivation (patient 8 in Table 3) was treated with lamivudine together with HCQ instead of MTX + LEF. Her serum ALT returned to normal and serum HBV-DNA returned to undetectable two months later. However, with relapsed disease activity (DAS28 = 3.6), she was then treated with MTX + HCQ and reached low disease activity 2 months later.

Treatment adjustment of DMARDs for 6 patients with HBV-DNA $\geq 10^{5}$ copies $/ \mathrm{mL}$ at reactivation was shown in Table 3. Patient 1 and patient 13 who have not accepted antiviral prophylaxis were prescribed antiviral therapy, and patient 1 chose lamivudine for economic reason. Patient 11 and 12 who have discontinued antiviral prophylaxis was prescribed antiviral therapy, and patient 11 chose lamivudine for economic reason. Patient 9 and 10 who have chosen lamivudine as antiviral prophylaxis were changed to adefovir dipivoxil and telbivudine, respectively. HBV-DNA of patient 1 returned to undetectable 11 months later. Serum ALT of patient $9 \sim 12$ returned to normal and serum HBV-DNA decreased 2 3 months later (still in follow-up). Patient 13 stopped all DMARDs after developing icteric hepatitis and decompensate cirrhosis.

\section{Discussion}

This study provided follow-up records of 36 RA patients with HBV carrier state ranging $12 \sim 70$ months in realworld clinical practice and the prevalence of HBV reactivation for RA patients with $\mathrm{HBV}$ carrier state during DMARDs therapy was found as high as $36 \%$ and the prevalence of HBV hepatitis together with reactivation was $17 \%$. Our study first highlighted poor patient acceptance and discontinuation of antiviral prophylaxis for
Chinese RA patients with HBV carrier state. Using survival curve and multivariate regression analysis, our results demonstrated two innovative risk factors of HBV reactivation for RA patients with $\mathrm{HBV}$ carrier state during DMARDs therapy, discontinuation of antiviral prophylaxis and past history of hepatitis.

DMARDs can cause unopposed HBV replication or reactivation in liver by suppressing host immune response (e.g. HBV-specific cytotoxic T lymphocyte) [11]. Therefore, $\mathrm{HBV}$ reactivation is described mainly on virological terms about serum HBV-DNA with a 10-fold rise or switching from undetectable to detectable. HBeAg seroconversion from negative to positive is also a definition of HBV reactivation. However, our result showed that none of $10 \mathrm{pa}-$ tients with $\mathrm{HBV}$ reactivation and negative $\mathrm{HBeAg}$ had $\mathrm{HBeAg}$ seroconversion. Abolishing or downregulating the production of $\mathrm{HBeAg}$ may be partly explained by mutations of the precore or basal core prompter [12]. Detection of serum HBV-DNA may be more important than $\mathrm{HBeAg}$ while monitoring the occurrence of $\mathrm{HBV}$ reactivation.

Clinical manifestations of HBV reactivation were attributed to elevated HBV-DNA replication and liver injury. Elevated HBV-DNA replication, although asymptomatic sometimes, can induce random integration of HBV-DNA into the host DNA in hepatocytes [6], leading to increased risk of hepatocarcinoma and decreased likelihood of HBV eradication. Liver injury manifests as elevated ALT with or without jaundice. Repeated high ALT peaks with failure to suppress HBV replication were shown to predict higher rates of cirrhosis [13]. Our results showed nearly half of RA patients with HBV reactivation developed HBV hepatitis and one patient developed decompensate cirrhosis, indicating poor outcomes of HBV reactivation for RA patients with HBV carrier state during DMARDs therapy.

Poor patient acceptance and discontinuation of antiviral prophylaxis should not be ignored for Chinese RA patients with HBV carrier state

Antiviral prophylaxis was recommended by ACR for RA patients with chronic HBV infection during DMARD 
treatment [8,9]. Entecavir and tenofovir, which are nucleotide analogs with high antiviral potency and a high barrier to resistance, are both recommended as first line antiviral drugs for patients who have a high HBV-DNA level and/or may receive a lengthy and repeated cycles of immunosuppression (e.g. long-term DMARDs therapy) by European [7], American [6] and Asian-Pacific [5] associations for the study of liver disease. However, in this realworld study, although all patients were recommended entecavir or tenofovir, only $50 \%$ of patients accepted lamivudine as antiviral prophylaxis. The most important reason was the cost of antiviral drug, which is much more expensive than conventional DMARDs causing high economic burden for self-paid RA patients, not only in developing countries but also in developed countries [14]. Lamivudine resistance (up to $70 \%$ in 5 years) usually occurs after 6-9 months of lamivudine therapy and is responsible for virus breakthrough [5]. Lamivudine resistance partly correlates with YMDD mutation, which develops in $15 \% \sim 30 \%$ per year of $\mathrm{HBV}$ patients on lamivudine prophylaxis [15]. Our results showed two patients with continuous lamivudine prophylaxis developed HBV reactivation and hepatitis 8 or 14 months later, with regret that YMDD motif mutation of $\mathrm{HBV}$ was not tested. Ryu et al. [16] reported one case of HBV reactivation occurred due to YMDD mutation after long-term use of lamivudine in a retrospective study included 15 patients received biological DMARDs under lamivudine prophylaxis.

Withdrawal of antiviral drug usually resulted in rebound of HBV-DNA, accompanying with "flare" of ALT in $19 \sim 50 \%$ of patients [17]. Our study showed $71 \%$ of patients who discontinued antiviral prophylaxis developed HBV reactivation $3 \sim 21$ months after discontinuation. Both survival curve and regression analysis proved that discontinuation of antiviral prophylaxis was risk factor of $\mathrm{HBV}$ reactivation for RA patients with $\mathrm{HBV}$ carrier state during DMARDs therapy. Therefore, discontinuation of antiviral prophylaxis may be important reason for high prevalence of HBV reactivation in our observational study. Thus, antiviral prophylaxis should be insisted once begun and continued minimal $6 \sim 12$ months after suspension of immunosuppressant. Rheumatologists should choose antiviral drugs according to guidelines and informing patients the serious consequences of antiviral drugs discontinuation at each interview.

Low-dose MTX may be alternative for RA patients with HBV carrier state to control RA disease activity, while LEF should be contraindicated

Not only the risk of HBV reactivation but also the effect of DMARDs on disease activity should be considered when choosing DMARDs for RA patients with HBV carrier state. HCQ, minocycline, SSZ or SSZ + HCQ which can be used for RA patients with HBV carrier state according to guidelines $[8,9]$ was sometimes inadequate to control moderate to high disease activity, while biologic DMARDs are usually expensive for self-paid patients. Although contraindicated by guidelines [8] MTX and/or LEF sometimes have to be used for controlling RA disease activity. One patient in our study had repeated relapse of RA disease activity when taking $\mathrm{HCQ}$ alone after $\mathrm{HBV}$ reactivation and $\mathrm{HBV}$ hepatitis. After lowdose MTX was added with HCQ, her disease activity was controlled to low disease activity.

In this real-world study, $72 \%$ of RA patients had moderate to high disease activity and MTX-based DMARD combination therapy had to be used. Our study showed the prevalence of $\mathrm{HBV}$ reactivation in patients taking MTX + LEF was $80 \%$, which was significantly higher than $21 \%$ in patients taking MTX alone or other MTXbased DMARD combination therapy. Further regression analysis showed LEF, but not MTX, was risk factor of DMARD-induced HBV reactivation. It was reported that LEF probably activated HBV replication by a nucleotidereduction-associated increase of mitogen-activated protein kinase (MAPK) p38 phosphorylation in vitro [18]. LEF is also a hepatotoxic drug causing transient elevation of serum ALT in more than 5\% of patients [19]. Therefore, LEF should be contraindicated for RA patients with HBV carrier state, while low-dose MTX may be alternative to control moderate to high RA disease activity. One literature review supported this assumption and showed most cases were treated with MTX as a preferred choice [20]. However, 21\% of patients taking MTX+ non-LEF DMARDs combination therapy developed HBV reactivation in our study and there are sporadic case reports on MTX-induced HBV reactivation [21-23]. Further prospective cohort study is required to explore the safety and effective of low-dose MTX+ non-LEF DMARDs combination therapy with antiviral therapy for RA patients with HBV carrier state.

Additionally, corticosteroid might promote HBV replication by activating glucocorticoid responsive elements (GRE) on HBV and the risk of high-dose corticosteroid on $\mathrm{HBV}$ reactivation in oncology-chemotherapy patients has been comfirmed [11]. Other than patients with hematology-oncology diseases or some other rheumatic diseases, low-dose glucocorticoids should be considered as part of the initial treatment strategy (in combination with one or more conventional DMARDs) for RA patients for up to 6 months, but should be tapered as rapidly as clinically feasible according to 2013 EULAR recommendations [24]. One small-scale prospective study showed coadministration of low-dose corticosteroid had a significant correlation with $\mathrm{HBV}$ reactivation among RA patients with HBV carrier state without antiviral prophylaxis [25]. Our study did not find corticosteroid as a risk factor of HBV 
reactivation for RA patients with $\mathrm{HBV}$ carrier state during DMARDs therapy. Since our study included more patients (81\%) taking low-dose corticosteroid, further study with larger sample size is needed to evaluate the exact risk of low-dose corticosteroid on HBV reactivation for RA patients with HBV carrier state during DMARDs therapy.

One of limitations in this study was lack of data about biologic DMARDs, since only 4 patients receiving TNF$\alpha$ antagonist for $4 \sim 6$ weeks were included. HBV reactivation occurred $21 \sim 24$ months after discontinuation of TNF- $\alpha$ antagonist in 3 patients, which might be attributed to subsequent conventional DMARDs, rather than TNF- $\alpha$ antagonist. Recently, Costa et al. [26] reported long-term use of TNF- $\alpha$ antagonist alone was safe for 15 psoriatic arthritis patients with chronic hepatitis $\mathrm{C}$ virus (HCV) infection in the absence of specific therapy for HCV. Giannitti et al. [27] reported tocilizumab combined with cyclosporine-A was effective and safe for a RA patient with chronic HCV infection. Cyclosporine-A could control $\mathrm{HCV}$ replication by inhibition of cyclophilin-B (while the inhibition of calcineurin causes immunosuppressive effect) and may be safe in patients with autoimmune disorders and concomitant HCV infection [28]. However, litter is known about the safety of cyclosporine-A in patients with RA and concomitant HBV infection. Additionally, RA patients who were $\mathrm{HBsAg}$-negative anti-HBc-positive potential occult carriers [29] should also be emphasized.

\section{Conclusions}

The results of our study suggest that poor patient acceptance and discontinuation of antiviral prophylaxis should not be ignored for Chinese RA patients with HBV carrier state in real-world clinical practice. Discontinuation of antiviral prophylaxis, past history of hepatitis and LEF might increase risk of HBV reactivation for RA patients with HBV carrier state during DMARDs therapy.

\section{Additional file}

Additional file 1: HBV serological markers for each patient both at baseline and at the end of follow-up*.

\footnotetext{
Abbreviations

HBV: Hepatitis B Virus; HBsAg: Surface Antigen of HBV; ALT: Alanine AminoTransferase; RA: Rheumatoid Arthritis; DMARDs: Disease Modifying Antirheumatic Drug; ACR: American College of Rheumatology; HCQ: Hydroxychloroquine; MTX: Methotrexate; LEF: Leflunomide; EULAR: European League Against Rheumatism; TBiL: Total Billirubin; HBsAb: Antibody to HBsAg; HBeAg: E Antigen of HBV; HBeAb: Antibody to HBeAg; HBcAb: Antibody to Core Antigen of HBV; OR: Odds ratio; Cl: Confidence interval; MAPK: Mitogen-Activated Protein Kinase; GRE: Glucocorticoid rresponsive elements; HCV: Hepatitis C virus.
}

\section{Competing interests}

The authors declare that they have no competing interests.

\section{Authors' contributions}

MYQ and LAQ contributed equally to this work, including conceiving and designing the study, advising on the search, reading and analyzing documents, and drafting the paper. Corresponding author DL also contributed to conceiving and designing the study, advising on the search, reading and analyzing documents, and editing the paper. MJD, CLF, JDH conducted the document search, read and analysed the documents. SHR advised on the search and edited the paper. All seven authors take responsibility for the content of the paper. All authors read and approved the final manuscript.

\section{Acknowledgements}

We would like to thank all patients who accepted this clinical follow-up. This work was supported by National Natural Science Foundation of China (grant no. 81471597), Specialized Research Fund for the Doctoral Program of Higher Education (Grant no.20130171110075) and Guangdong Natural Science Foundation, China (Grant no.S2013010014396) to L. Dai; Medical Scientific Research Foundation of Guangdong Province, China (Grant no. A2013201) to Y-Q. Mo.

\section{Author details}

${ }^{1}$ Department of Rheumatology, Sun Yat-sen Memorial Hospital, Sun Yat-Sen University, 107\# Yan Jiang West Road, Guangzhou 510120, People's Republic of China. 'Division of Rheumatology, VA Medical Center, University of Pennsylvania, University \& Woodland Aves, Philadelphia, PA, USA.

Received: 9 June 2014 Accepted: 16 December 2014

Published: 22 December 2014

\section{References}

1. Liang X, Bi S, Yang W, Wang L, Cui G, Cui F, Zhang Y, Liu J, Gong X, Chen Y, Wang F, Zheng H, Wang F, Guo J, Jia Z, Ma J, Wang H, Luo H, Li L, Jin S, Hadler SC, Wang Y: Epidemiological serosurvey of hepatitis B in Chinadeclining HBV prevalence due to hepatitis B vaccination. Vaccine 2009, 27:6550-6557.

2. Liaw YF, Chu CM: Hepatitis B virus infection. Lancet 2009, 373:582-592.

3. Zou CJ, Zhu LJ, Li YH, Mo YQ, Zheng DH, Ma JD, Ou-Yang X, Pessler F, Dai $L$ : The association between hepatitis $B$ virus infection and disease activity, synovitis, or joint destruction in rheumatoid arthritis. Clin Rheumatol 2013, 32:787-795.

4. Vassilopoulos D, Calabrese LH: Management of rheumatic disease with comorbid HBV or HCV infection. Nat Rev Rheumatol 2012, 8:348-357.

5. Liaw YF, Kao JH, Piratvisuth T, Chan LY, Chien RN, Liu CJ, Gane E, Locarnini S, Lim SG, Han KH, Amarapurkar, Cooksley G, Jafri W, Mohamed R, Hou JL, Chuang WL, Lesmana LA, Sollano JD, Suh DJ, Omata M: Asian-Pacific consensus statement on the management of chronic hepatitis B: a 2012 update. Hepatol Int 2012, 6:531-561.

6. Lok AS, McMahon BJ: Chronic hepatitis B: update 2009. Hepatology 2009, 50:661-662

7. European Association For The Study Of The Liver: EASL clinical practice guidelines: management of chronic hepatitis B virus infection. $J$ Hepatol 2012, 57:167-185.

8. Saag KG, Teng GG, Patkar NM, Anuntiyo J, Finney C, Curtis JR, Paulus HE, Mudano A, Pisu M, Elkins-Melton M, Outman R, Allison JJ, Suarez Almazor M, Bridges SL Jr, Chatham WW, Hochberg M, MacLean C, Mikuls T, Moreland LW, O'Dell J, Turkiewicz AM, Furst DE, American College of Rheumatology: American College of Rheumatology 2008 recommendations for the use of nonbiologic and biologic disease-modifying antirheumatic drugs in rheumatoid arthritis. Arthritis Rheum 2008, 59:762-784.

9. Singh JA, Furst DE, Bharat A, Curtis JR, Kavanaugh AF, Kremer JM, Moreland LW, O'Dell J, Winthrop KL, Beukelman T, Bridges SL Jr, Chatham WW, Paulus HE, Suarez-Almazor M, Bombardier C, Dougados M, Khanna D, King CM, Leong AL, Matteson EL, Schousboe JT, Moynihan E, Kolba KS, Jain A, Volkmann ER, Agrawal H, Bae S, Mudano AS, Patkar NM, Saag KG: 2012 update of the 2008 American College of Rheumatology recommendations for the use of disease-modifying antirheumatic drugs and biologic agents in the treatment of rheumatoid arthritis. Arthritis Care Res (Hoboken) 2012, 64:625-639.

10. Yeo W, Chan PK, Zhong S, Ho WM, Steinberg JL, Tam JS, Hui P, Leung NW, Zee $B$, Johnson PJ: Frequency of hepatitis $B$ virus reactivation in cancer patients undergoing cytotoxic chemotherapy: a prospective study 
of 626 patients with identification of risk factors. J Med Virol 2000, 62:299-307.

11. Hwang JP, Lok AS: Management of patients with hepatitis B who require immunosuppressive therapy. Nat Rev Gastroenterol Hepatol 2014 11:209-219.

12. Liaw YF: Natural history of chronic hepatitis B virus infection and longterm outcome under treatment. Liver Int 2009, 29(Suppl 1):100-107.

13. Tai DI, Lin SM, Sheen IS, Chu CM, Lin DY, Liaw YF: Long-term outcome of hepatitis B e antigen-negative hepatitis B surface antigen carriers in relation to changes of alanine aminotransferase levels over time. Hepatology 2009, 49:1859-1867.

14. Malespin M, Wong S, Siqueira F, Luc B, Ravaee B, Vainder C, Cotler SJ: Barriers to treatment of hepatitis $B$ in an urban Chinatown community. J Clin Gastroenterol 2012, 46:e66-e70.

15. Dienstag JL: Hepatitis B virus infection. N Engl J Med 2008, 359:1486-1500.

16. Ryu HH, Lee EY, Shin K, Choi IA, Lee YJ, Yoo B, Park MC, Park YB, Bae SC, Yoo WH, Kim SI, Lee EB, Song YW: Hepatitis B virus reactivation in rheumatoid arthritis and ankylosing spondylitis patients treated with anti-TNFa agents: a retrospective analysis of 49 cases. Clin Rheumatol 2012, 31:931-936.

17. Lim SG, Wai CT, Rajnakova A, Kajiji T, Guan R: Fatal hepatitis B reactivation following discontinuation of nucleoside analogues for chronic hepatitis B. Gut 2002, 51:597-599.

18. Hoppe-Seyler K, Sauer P, Lohrey C, Hoppe-Seyler F: The inhibitors of nucleotide biosynthesis leflunomide, FK778, and mycophenolic acid activate hepatitis B virus replication in vitro. Hepatology 2012, 56:9-16.

19. Emery P, Breedveld FC, Lemmel EM, Kaltwasser JP, Dawes PT, Gömör B, Van Den Bosch F, Nordström D, Bjorneboe O, Dahl R, Horslev-Petersen K Rodriguez De La Serna A, Molloy M, Tikly M, Oed C, Rosenburg R, LoewFriedrich I: A comparison of the efficacy and safety of leflunomide and methotrexate for the treatment of rheumatoid arthritis. Rheumatology (Oxford) 2000, 39:655-665.

20. Xuan D, Yu Y, Shao L, Wang J, Zhang W, Zou H: Hepatitis reactivation in patients with rheumatic diseases after immunosuppressive therapy-a report of long-term follow-up of serial cases and literature review. Clin Rheumatol 2014, 33:577-586.

21. Gwak GY, Koh KC, Kim HY: Fatal hepatic failure associated with hepatitis B virus reactivation in a hepatitis $B$ surface antigen-negative patient with rheumatoid arthritis receiving low dose methotrexate. Clin Exp Rheumatol 2007, 25:888-889.

22. Ostuni $P$, Botsios $C$, Punzi L, Sfriso P, Todesco S: Hepatitis B reactivation in a chronic hepatitis $B$ surface antigen carrier with rheumatoid arthritis treated with infliximab and low dose methotrexate. Ann Rheum Dis 2003, 62:686-687.

23. Ito S, Nakazono K, Murasawa A, Mita Y, Hata K, Saito N, Kikuchi M, Yoshida K, Nakano M, Gejyo F: Development of fulminant hepatitis B (precore variant mutant type) after the discontinuation of low-dose methotrexate therapy in a rheumatoid arthritis patient. Arthritis Rheum 2001, 44:339-342.

24. Smolen JS, Landewé $R$, Breedveld $F C$, Buch $M$, Burmester $G$, Dougados $M$, Emery P, Gaujoux-Viala C, Gossec L, Nam J, Ramiro S, Winthrop K, de Wit M, Aletaha D, Betteridge N, Bijlsma JW, Boers M, Buttgereit F, Combe B, Cutolo M, Damjanov N, Hazes JM, Kouloumas M, Kvien TK, Mariette X, Pavelka K, van Riel PL, Rubbert-Roth A, Scholte-Voshaar M, Scott DL, Sokka-Isler T, Wong JB, van der Heijde D: EULAR recommendations for the management of rheumatoid arthritis with synthetic and biological disease-modifying antirheumatic drugs: 2013 update. Ann Rheum Dis 2014, 73:492-509.

25. Tan J, Zhou J, Zhao P, Wei J: Prospective study of HBV reactivation risk in rheumatoid arthritis patients who received conventional diseasemodifying antirheumatic drugs. Clin Rheumatol 2012, 31:1169-1175.

26. Costa L, Caso F, Atteno M, Giannitti C, Spadaro A, Ramonda R, Vezzù M, Del Puente A, Morisco F, Fiocco U, Galeazzi M, Punzi L, Scarpa R: Long-term safety of anti-TNF-a in PsA patients with concomitant HCV infection: a retrospective observational multicenter study on 15 patients. Clin Rheumatol 2014, 33:273-276.

27. Giannitti C, Fineschi I, Frediani B, Fioravanti A, Galeazzi M: Efficacy and safety of tocilizumab combined with cyclosporine $A$ in a patient with rheumatoid arthritis and concomitant chronic hepatitis $C$ virus infection. Clin Exp Rheumatol 2013, 31:816.
28. Galeazzi M, Bellisai F, Giannitti C, Manganelli S, Morozzi G, Sebastiani GD: Safety of cyclosporin A in HCV-infected patients: experience with cyclosporin A in patients affected byrheumatological disorders and concomitant HCV infection. Ann N Y Acad Sci 2007, 1110:544-549.

29. Giannitti C, Sebastiani GD, Manganelli S, Galeazzi M: Safety of anti-tumor necrosis factor agents in rheumatic potential carriers of occult hepatitis B virus. J Rheumatol 2011, 38:780-781.

doi:10.1186/1471-2474-15-449

Cite this article as: Mo et al: Discontinuation of antiviral prophylaxis correlates with high prevalence of hepatitis B virus (HBV) reactivation in rheumatoid arthritis patients with HBV carrier state: a real-world clinical practice. BMC Musculoskeletal Disorders 2015 15:449.

\section{Submit your next manuscript to BioMed Central and take full advantage of:}

- Convenient online submission

- Thorough peer review

- No space constraints or color figure charges

- Immediate publication on acceptance

- Inclusion in PubMed, CAS, Scopus and Google Scholar

- Research which is freely available for redistribution

Submit your manuscript at www.biomedcentral.com/submit
C Biomed Central 